\title{
Testing a model of absence and intent to stay in employment : a study of registered nurses in Malta
}

\author{
Roberta Gauci Borda* and Ian J. Norman ${ }^{\mathrm{b}}$ \\ ${ }^{a}$ Institute of Health Care, University of Malta, Malta \\ ${ }^{b}$ Department of Nursing Studies, King's College, University of London, London, U.K
}

(Received 1 March 1997; revised 30 June 1997)

\begin{abstract}
This study used a cross-sectional, correlational design to test a model of absence and turnover of registered nurses developed from a review of the research literature (Gauci Borda and Norman, 1997). Testing the model involved comparing the relationship between job satisfaction, kinship responsibility, pay, employment opportunity, intent to stay in employment and absence for male and female registered nurses. All registered nurses $(n=254)$ working in clinical areas on a full-time shift basis, in one large general hospital in Malta were surveyed by questionnaire and their absence data were obtained from the hospital personnel records. A response rate of $67 \%(n=171)$ was achieved. The results showed that nurses were satisfied with their job and intended to stay in their present employment for the next 12 months. Relationships between variables differed between male and female nurses, with job satisfaction being associated with intent to stay for male nurses but not for females and kinship responsibility and intent to stay being associated with absence in female but not male nurses. In contrast to many previous studies of nurses, an association was found between job satisfaction and absence. Several variables, including fear of change, which may influence intent to stay of Maltese nurses, were identified. The proposed model of absence and turnover stood up reasonably well to testing, but the results for the whole sample, and the sub-samples of male and female nurses supported different parts of the model. The main implication for future research is that male and female nurses should be studied separately due to differences found between the two groups. C 1997 Elsevier Science Ltd. All rights reserved.
\end{abstract}

\section{Background}

A review of research studies investigating retention and absence of nurses (Gauci Borda and Norman. 1997) showed that the variable most strongly associated with qualificd nurses' turnover was intent to leave their present employment, and that this variable was strongly associated with job satisfaction. Although several other variables, besides job satisfaction, were reported in studies as influencing intent to stay, the correlation between job satisfaction and intent to stay, is consistently stronger than that found for other variable (Cavanagh and Coffin, 1992; Parasuranam, 1989; Seybolt, 1986; Michaels and Spector, 1982; Price and Mueller, 1981). Of these variables, kinship responsibility, opportunity for work outside the present employment and pay are supported by two studies-Cavanagh and Coffin (1992), and Price and Mueller (1981). Other variables were supported by the

* To whom correspondence should be addressed : Roberta Gauci Borda, Institute of Health Care, University of Malta, Guardamangia, Malta. results of single studies and have not been confirmed. The relationship between job satisfaction and absence was less strongly supported by the literature. In fact none of the nursing studies reviewed found a significant relationship (Matrunola, 1996; Burton, 1992; $\mathrm{Ng}, 1991$; Price and Mueller, 1986; Redfern. 1981; Clark, 1975). However, such a relationship cannot be discounted before other reasons for lack of correlation, such as the use of different measures of absence and inappropriate data analytical techniques, are examined and discounted (Brooke, 1986; Nicholson, 1977). Kinship responsibility which was shown to influence intent to stay was also reported in the literature to influence absence of nurses (Lee and Eriksen, 1990; Miller and Norton, 1986; Burton, 1992; Steers and Rhodes, 1978; Redfern, 1978). Kinship responsibility was expected to deter absence of male nurses and increase absence of female nurses (Burton, 1992; Miller and Norton, 1986).

Our research review (Gauci Borda and Norman, 1997) revealed that only a small number or no male nurses were included in the research studies. Also only one study (Nichols, 1971) was identified which conI- 
pared male and female nurses on job satisfaction and intent to stay. This study showed that, although there was no difference in job satisfaction of male and female nurses, intent to leave was higher for female married nurses than unmarried femalc nurses. No difference was found in intent to stay of unmarried and married male nurses. This suggests that different dynamics influence male and female workers and that strategies to improve retention of nurses, who are a predominantly female workforce, must take this into account if they are to be effective (Buchan, 1994). No studies were found comparing male and female nurses on the relationship between job satisfaction and absence.

On the basis of our research review a hypothetical model of absence and turnover, was developed which was grounded in the research literature. The purpose of the study reported here was to test this model in relation to registered nurses working in one general hospital in Malta.

\section{Method}

\section{Aims, objectives and hypotheses}

The aim of this study was to test the hypothetical model of absence and turnover illustrated in Fig. 1. The model depicts the expected relationship between the variables and is composed of attitudinal (job satisfaction), decisional (behavioural intention), economic (pay and employment opportunity), social (kinship responsibility) and behavioural (absence and turnover) components. The arrows show the expected direction of the relationship between the variables and their expected relative importance; the dotted arrows indicate that the correlation is expected to be lower than those depicted by solid arrows. The adjacent plus signs, indicate that the variables are expected to be directly related, whilst the minus signs indicate that an inverse relationship is expected.

The objective of this study were to compare male and female registered nurses on the relationship between:

- job satisfaction and intent to stay in employment;

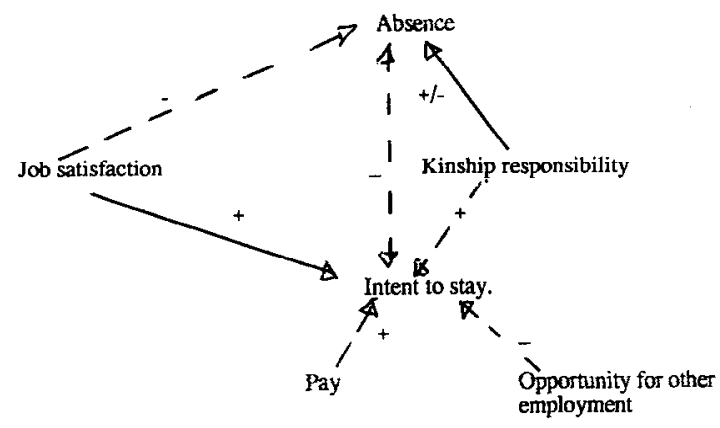

Fig. 1. Proposed model of the relationship between absence and turnover and job satisfaction, intent to stay, and other variables (pay, kinship responsibility, opportunity for employment).
- job satisfaction and absence ;

- pay, opportunity for work outside present employment, kinship responsibility and intent to stay in present employment;

- kinship responsibility and absence;

- intent to stay in present employment and absence.

The hypotheses based on the model (Fig. 1) are:

1. The higher nurses' job satisfaction, the higher their intent to stay.

2. The higher nurses' job satisfaction the lower the frequency of one- and two-day absence.

3. The higher the intent to stay the lower the frequency of one- and two-day absences.

4. Job satisfaction has a greater influence on intent to stay than other variables (i.e. kinship responsibility, pay, employment opportunity).

5. Kinship responsibility is directly related to frequency of one- and two-day absences in females and inversely related for males.

These hypotheses were tested separately for male and female registered nurses and differences between the two identified.

\section{Research site and sample}

The study was conducted in a 1000-bed state-owned general hospital in Malta. Respondents were qualified registered nurses, directly involved in delivery of nursing care to patients in acute clinical areas, and working full time on a shift basis. The total population of nurses eligible for inclusion according to these criteria $(n=254)$ were invited to participate. They included nurses on a variety of wards including general medi$\mathrm{cal} /$ surgical, paediatrics, perinatal, intensive care and speciality units such as neurosurgery and operating theatres.

\section{The research instruments}

The nurses were surveyed by questionnaire and their personnel records were reviewed for sickness and absence data.

\section{Questionnaire}

The questionnaire combined six scales all of which had been tested previously for validity and reliability. The content of the questionnaire is summarised in Fig. 2. The problem inherent in using questionnaires in studies on job satisfaction, is that important aspects of the reasons why any individual decides to withdraw and information on feelings and values may be ignored (Taylor, 1977 ; Porter and Steers, 1973). Following Cavanagh (1989) and Metcalf (1986), three open questions were therefore included to allow respondents to include aspects not covered by the questionnaire and give reasons for their answers to the fixed choice questions.

The questionnaire was tested in a pilot study in 


\begin{tabular}{|c|c|}
\hline VARIABLE & MEASURE \\
\hline Job satisfaction & SECTION I \\
\hline Overall & Global satisfaction index (Lyons, 1971) \\
\hline \multirow[t]{2}{*}{ With job facets } & Mueller/McCloskey Satisfaction Scale (1990) \\
\hline & $\begin{array}{l}\text { Open question for further comments/explanation } \\
\text { of answers. }\end{array}$ \\
\hline & SECTION II \\
\hline Importance of job facets to remaining in the job. & $\begin{array}{l}\text { Adapted from Mueller/McCloskey Satisfaction } \\
\text { Scale (1990). }\end{array}$ \\
\hline Intent to stay & $\begin{array}{l}\text { Propensity to Leave Index adapted by } \\
\text { Redfern (1981) from Lyons (1971). }\end{array}$ \\
\hline & $\begin{array}{l}\text { Two open questions to give explanations } \\
\text { of intent to leave/stay. }\end{array}$ \\
\hline Opportunity for employment & Four items from Price and Mueller (1981). \\
\hline Kinship responsibility & $\begin{array}{l}\text { SECTION III } \\
\text { Three items from Price and Mueller (1981) and } \\
\text { two additional items on age of children and } \\
\text { looking after relatives outside nuclear family. }\end{array}$ \\
\hline Demographic data & Six questions. \\
\hline Pay & $\begin{array}{l}\text { Three items adapted from Price and Mueller } \\
\text { (1981). }\end{array}$ \\
\hline Absence & $\begin{array}{l}\text { Attitudinal Index: number of absence spells } \\
\text { lasting one or two days during past year. } \\
\text { Frequency of } 1,2 \text { and } 3 \text { day absence spells, } \\
\text { Short term absence (lasting three days or less) } \\
\text { frequency of absence lasting four or more days, } \\
\text { total number of absence spells in previous year, } \\
\text { total number of days absent in previous year. }\end{array}$ \\
\hline
\end{tabular}

Fig. 2. Summary of questionnaire content.

January 1995. It was completed by 10 Maltese nurses not included in the main study who found the questionnaire readily comprehensible. No major changes in structure or content of the questionnaire were needed.

\section{Absence data recording sheet}

A data recording sheet was designed to record the absence data of respondents from hospital personnel records. It was expected that the "attitudinal index" (frequency of one-day and two-day absence) would be most strongly correlated to job satisfaction since it is a reliable measure of "avoidable" absence, that is absence not related to sickncss. Thus the attitudinal index would be the measurement of choice to correlate to job satisfaction which is an attitudinal variable (Chadwick-Jones et al., 1971). Several other measures of absence, as specified in Fig. 2, were included, though, to provide a more holistic picture of the absence problem (Clark, 1975). This allowed the absence measures which are most strongly related to job satisfaction to be identified.

\section{Data collection procedures}

Main study data were collected over 11 days in February 1996. Questionnaires were distributed and 
collected personally by one of the research team, to encourage participation by respondents. This was not possible however for nurses working in operating theatres due to restricted access and so, for them, questionnaires were left at a central point for collection. Absence data were collected on participating respondents retrospectively for a period of one year, from February 1995 to February 1996.

The data were analysed using descriptive and infercntial statistics. Spearman's correlation coefficient was used to test for relationships between the variables; all tests were two-tailed.

\section{Access and ethical issues}

The main ethical issues involved in this study are respondents' right to self-determination, anonymity and confidentiality. The last two were particularly important as the study involved respondents' place of employment. For this reason, respondents were given full information on the nature of the study and their consent was obtained before being included. Questionnaires were kept confidentially and participants were assured of their right to withdraw at any time. The names of the respondents were not recorded on the questionnaire. All data were rendered anonymous.

\section{Findings}

\section{Response rate}

A sample size of 171 was obtained from the targeted population of 254 registered nurses, giving a response rate of $67 \%$. The response rates for the female and male sub-samples were nearly the same, $66 \%$ for the female nurses and $68 \%$ for the male nurses. The only information available about non-respondents was their gender and place of work. There were no significant differences between respondents and nonrespondents on the variable of gender, however a much larger proportion of non-respondents than respondents were working in the operating theatres where the lowest response rate $(38 \%)$ was obtained. This is probably because access to the operating theatres was barred, which meant that nurses in these areas could not be approached personally and asked to participate.

\section{Job satisfaction}

The majority of the nurses $(61 \%, n=104)$ were satisfied with their job as a whole and $63 \%(n=108)$ intended to remain in their jobs for the next 12 months. The areas of greatest satisfaction were: the delivery of care method used $(64 \%, n=110)$; their nursing peers $(64 \%, n=108)$; the doctors with whom they worked $(64 \%, n=110)$; their amount of responsibility $(62 \%, n=107)$; immediate supervisors $(59 \%, n=101)$; their salary $(51 \% ; n=87)$; and recognition from peers $(47 \%, n=80)$. Aspects of greatest dissatisfaction were: child care facilities $(71 \%, n=122)$; flexibility in scheduling hours of work $(70 \%, n=120)$; weekends off $(65 \%, n=112)$; opportunity to write and publish $(65 \%, n=112)$; opportunity to participatc in nursing research $(62 \%$, $n=105$ ); and opportunities for career advancement $(61 \%, n=105)$.

Spearman's rank order correlation coefficient revealed a significant positive relationship between job satisfaction and intent to stay $\left(r_{s}=0.48, P<0.005\right)$ for the total sample. A significant positive relationship between job satisfaction and intent to stay was also found for both the male and female nurses. The relationship for males was, however, stronger $\left(r_{s}=0.63\right.$, $P<0.005)$ than that for female nurses $\left(r_{s}-0.33\right.$, $P<0.005$ ).

\section{Job satisfaction and absence}

Correlation coefficients between job satisfaction and measures of absence are shown in Table 1. There was no significant relationship between global job satisfaction and the attitudinal index $\left(r_{s}=-0.12\right)$ for the total sample. Of the other measures of absence, a significant negative relationship was found between job satisfaction and frequency of one day absence $\left(r_{s}=-0.14, P<0.05\right)$ and between job satisfaction and short term absence $\left(r_{s}=-0.14, P<0.05\right)$ for the total sample. Correlation coefficients are very low however.

A significant negative relationship between job satisfaction and absence was found only between job satisfaction and one-day absence for the female registered nurses $\left(r_{\mathrm{s}}=-0.20, P<0.05\right)$. For the male nurses, however, significant relationship (all negative) were found between job satisfaction and frequency of three-, four- or more days absence, short term absence, total number of days absent in previous year and total number of absence spells in the previous year. The strongest relationship found was that between job satisfaction and frequency of absence spells lasting three days $\left(r_{s}=-0.23, P<0.025\right)$. No significant relationship was found between job satisfaction and the attitudinal index for either male or female registered nurses.

\section{Intent to stay and absence}

Correlation coefficients between intent to stay in present employment and absence are shown in Table 2. A significant negative relationship was found between intent to stay and absence with all the measures of absence, except for frequency of one-day absence spells, for the total sample. The corrclation coefficient for the attitudinal index and intent to stay was $-0.13(P<0.05)$ for the total sample. The strongest relationships found, though, were between intent to stay and total number of days absent during the previous year $\left(r_{s}=-0.21, \quad P<0.005\right)$ and 
Table 1.

Summary of correlation coefficients between job satisfaction and absence for male and female registered nurses

\begin{tabular}{|c|c|c|c|c|}
\hline \multirow[b]{2}{*}{ Job satisfaction and: } & \multicolumn{2}{|c|}{ Males } & \multirow{2}{*}{\multicolumn{2}{|c|}{$\begin{array}{c}\text { Females } \\
P\end{array}$}} \\
\hline & $r_{s}$ & $P$ & & \\
\hline Frequency of absence spells lasting one day & -0.09 & N.S. & -0.20 & $<0.05$ \\
\hline Frequency of absence spells lasting two days & -0.02 & N.S. & -0.01 & N.S. \\
\hline Frequency of absence spells lasting three days & -0.23 & $<0.025$ & 0.15 & N.S. \\
\hline Frequency of absence spells lasting four or more days & -0.20 & $<0.05$ & 0.01 & N.S. \\
\hline Attitudinal index & -0.09 & N.S. & -0.16 & N.S. \\
\hline Short-term absence & -0.20 & $<0.05$ & -0.09 & N.S. \\
\hline Total no. of days absent/year & -0.21 & $<0.05$ & -0.05 & N.S. \\
\hline Total no. of absence spells/year & $-0.21 \mathrm{p}$ & $<0.05$ & -0.06 & N.S. \\
\hline
\end{tabular}

N.S., not significant.

between intent to stay and frequency of absence spells lasting four or more days $\left(r_{s}=-0.19, P<0.01\right)$.

For the sub-sample of male nurses no significant relationship between any of the absence measures and intent to stay was found. For the sub-sample of female nurses, however, a significant negative relationship was found between intent to stay and all the measures of absence, except for frequency of one-day absences. The latter, however, was very close to the statistically significant value $(-0.18, P=0.05)$. The strongest relationship was found between intent to stay and total number of days absent in the previous year. The correlation coefficient between intent to stay and the attitudinal index was $-0.22(P<0.025)$.

There was no significant relationship between pay, opportunity, kinship responsibility and intent to stay for the total sample or for the sub-samples of female and male registered nurses.

Kinship responsibility and absence, as measured by the attitudinal index $\left(r_{s}=0.09\right)$ were not significantly related for the total sample. But a significant positive relationship was found with two of the other measures of absence, short-term absence $\left(r_{s}=0.13, P<0.05\right)$ and total number of absence spells in the previous year $\left(r_{s}=0.14, P<0.05\right)$.

There was no significant relationship between kin- ship responsibility and any of the absence measures for the male nurses. Significant positive relationships were found, however, for female nurses between kinship responsibility and all of the absence measures, except for frequency of one-day and four-day absences or longer. The strongest relationship found was that between kinship responsibility and total number of absence spells in the previous year $\left(r_{s}=0.29 ; P<0.005\right)$. Table 3 summarises the correlation values obtained.

\section{The hypotheses}

We summarise the main findings with reference to the five hypotheses previously identified.

Hypothesis 1-The higher nurses' job satisfaction, the higher their intent to stay

This hypothesis was supported by the results for the total sample and the male and female nurses. The size of the correlation, however, varied and was strongest for the male nurses.

Table 2 .

Summary of corrclation coefficients between intent to stay and absence for male and female registered nurses

\begin{tabular}{lrrrr}
\hline & \multicolumn{2}{c}{ Males } & \multicolumn{2}{c}{ Females } \\
Intent to stay and : & $r_{s}$ & $P$ & $r_{s}$ & $P$ \\
\hline Frequency of absence spells lasting one day & 0.01 & N.S. & -0.18 & N.S. \\
Frequency of absence spells lasting two days & -0.13 & N.S. & -0.19 & $<0.05$ \\
Frequency of absence spells lasting three days & -0.08 & N.S. & -0.21 & $<0.025$ \\
Frequency of absence spells lasting four or more days & -0.13 & N.S. & -0.26 & $<0.01$ \\
Absence index & -0.05 & N.S. & -0.22 & $<0.025$ \\
Short Absence & -0.10 & N.S. & -0.24 & $<0.025$ \\
Total no. of days absent/year & -0.13 & N.S. & -0.31 & $<0.005$ \\
Total no. of absence spells/year & 0.08 & N.S. & -0.26 & $<0.01$ \\
\hline
\end{tabular}

N.S., not significant. 
Table 3.

Correlation coefficients between kinship responsibility and absence for male and female registered nurses

\begin{tabular}{lcccc}
\hline & & Males & & \multicolumn{2}{c}{ Females } \\
Kinship responsibility and: & $r_{s}$ & $P$ & & $r_{s}$ \\
\hline Frequency of one day absence & -0.03 & N.S. & 0.05 & N.S. \\
Frequency of two day absence & -0.13 & N.S. & 0.25 & $<0.01$ \\
Frequency of three day absence & -0.06 & N.S. & 0.19 & $<0.05$ \\
Frequency of absence for four or more days & -0.10 & N.S. & 0.16 & N.S. \\
Attitudinal index & -0.04 & N.S. & 0.19 & $<0.05$ \\
Short term absence & -0.01 & N.S. & 0.23 & $<0.025$ \\
Total no. of days absent/year & -0.08 & N.S. & 0.20 & $<0.05$ \\
Total no. of absence spells/year & -0.05 & N.S. & 0.29 & $<0.005$ \\
\hline
\end{tabular}

N.S., not significant.

Hypothesis 2-The higher nurses' job satisfaction, the lower the frequency of absence lasting two days or less

This hypothesis was not supported. Significant negative correlations were found between job satisfaction and short-term absence for the total sample, frequency of three-day absence for male nurses and frequency of one-day absence for female nurses. These correlations, however, were low.

Hypothesis 3-The higher intent to stay, the lower the frequency of one-and two-day absences

This hypothesis was not supported. Significant negative correlations were, however, found between intent to stay and total number of days absent in the previous year for female nurses and the total sample. This relationship was stronger for the female than the male nurses, but was still relatively weak.

Hypothesis 4-Job satisfaction has a greater influence on intent to stay than the other variables: (pay, kinship responsibility or employment opportunity)

This hypothesis was supported as no relationship was found between kinship responsibility, pay, employment opportunity and intent to stay.

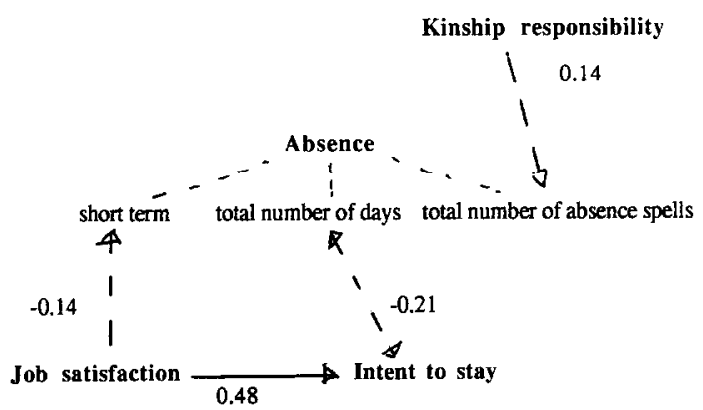

Fig. 3. Variant of the proposed model showing relationships between variables for the total sample.
Hypothesis 5-Kinship responsibility is directly related to frequency of absence lasting two days or less for females and inversely related for males

No relationship was found between kinship responsibility and the absence index. Kinship responsibility was, though, found to be significantly and positively related to the total number of absence spells in the previous year for the female nurses.

\section{Discussion}

The model proposed in Fig. 1 was not totally supported by the results of this study. In fact, three variants of the proposed model emerged, as the results for the whole sample, and the sub-samples of male and female registered nurses supported different parts of the model; these three variants of the original model are illustrated in Figs 3, 4, and 5. A relationship between absence and kinship responsibility and absence and intent to stay was found for females but not males. A negative relationship between job satisfaction and absence was found for male and female nurses and the total sample, but the absence measures to which job satisfaction was related differed. This suggests that job satisfaction is not such an important determining factor of intent to stay in present employment for female nurses as for male nurses.

The results of this study confirm those of previous studies which consistently show a positive relationship between job satisfaction and intent to stay. The results show, however, that job satisfaction is a stronger determining factor of intent to stay for male than

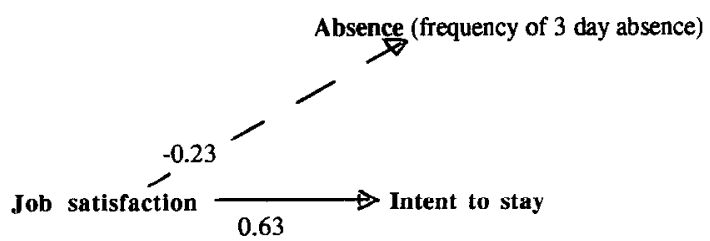

Fig. 4. Variant of the proposed model showing relationships between variables for male registered nurses. 


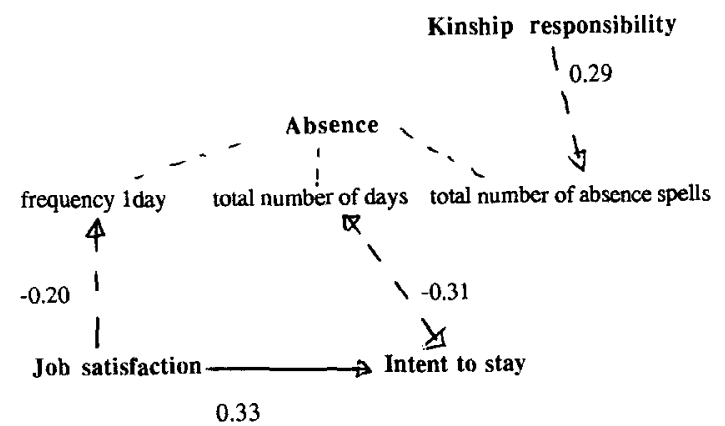

Fig. 5. Variant of the proposed model showing relationships between variables for female registered nurses.

female nurses (Fig. 4). This finding may also help explain variations in the strength of the relationship between the variables in previous studies (Gauci Borda and Norman, 1997) as this will vary with different samples including different numbers of male and female nurses.

In contrast to the results of Price and Mueller (1981) and Cavanagh and Cotfin's (1992) studies, no relationship was found between kinship responsibility, pay, opportunity for work outside the present employment and intent to stay for either male or female registered nurses.

Our finding of no relationship between kinship responsibility and intent to stay, even for female nurses, may mean that nurses leave their present employment for a combination of reasons; for example, being expected to look after their families, together with lack of child care facilities and lack of flexible hours of work required by nurses who are married, or have children, or other family commitments. This possible explanation is supported by our finding that child-care facilities and flexibility in working hours were amongst the areas of greatest dissatisfaction. It is also supported by responses to the open questions, of which the following are typical of many:

\footnotetext{
"Both my husband and I wish that I could continue working but because there are no facilities for mothers-child care-and hours are very long I will have to leave my profession to look after my child."

"The shift is a problem for me because of the long hours of work I hardly see my husband."

"I need more time with the children."
}

No relationship between pay and intent to stay is consistent with our finding that the majority of respondents were satisfied with their pay. This is supported by Knowles (1964) who states that "expected wage", that is the amount of pay the person perceives as fairly meeting his contribution, is a better predictor of intent to stay in employment than the wage itself.

Lack of association between opportunity for other employment and intent to stay is consistent with the findings of other studies (e.g. Michaels and Spector,
1982). Responses to the open questions showed that many respondents valued the security provided by working in the public sector:
"Government hospital-certain amount of security as hospital cannot become bankrupt."
"I suppose the fact that this hospital offers job secur- ity because it is the government hospital and will always need nurses."

In view of the shortage of nurses in Malta, it is perhaps surprising that the nurses viewed job security as being important when jobs are available in the private health care sector.

Another factor highlighted by the responses to the open questions was a fear of and reluctance to change. For example :

\footnotetext{
"I'm not the type of person that likes changes in my lifestyle-somewhat I'm afraid to leave. Once I get used to something I usually stick to it."

"I have grown my roots at my workplace."

"I have been working very long here, getting to know all the people and I think it would not be very easy to settle in a new job."

"It is a difficult decision to change,"
}

Other reasons given by respondents for staying on, was the need for money to pay for marriage expenses and house loans.

Unlike other studies of nurses, a significant relationship was found in this study between job satisfaction and absence for the total sample and for the male and female nurses (see Figs 3, 4 and 5). The strength of this relationship is weak however, as found in studies outside nursing (Farrell and Stamm, 1988; Hackett and Guion, 1985; Scott and Taylor, 1985; Newman, 1974). All these studies confirm Locke's (1976) observation that the magnitude of the relationship between job satisfaction and absence seldom surpasses -0.4 and is typically, as in the present study, much lower. This is consistent with Chadwick-Jones et al. (1971) and Nicholson et al.'s (1976) view that, at best, job satisfaction and absence from work are only tenuously related.

Hackett and Guion (1985) state that these weak relationshins between job satisfaction and absence could be statistical artefacts, as a result of large sample sizes. Hammer and Landau (1981), on the other hand, argue that the reason for the small correlations is the non-normal distribution of absence.

Steer and Rhodes (1978) argue that the reason for a low correlation between job satisfaction and absence is that most studies assume that the individual is free to choose whether to be absent or not, whilst this is not always so. In the present study, for example, all absence must be certified and anyone absent can expect a home visit by a doctor who confirms whether he is ill or not. These measures serve as incentives for employees not to be absent unless they are ill and so 
may attenuate the relationship between job satisfaction and avoidable absence. This incentive/reward system used in the hospital is suggested by Steers and Rhodes (1978) as one of the possible moderating variables in the relationship between job satisfaction and absence. Farrell and Stamm's (1988) meta-analysis found control policies and sections to be strongly and negatively correlated to absence. The results of this study support Steers and Rhodes (1978) assertion that the relationship between job satisfaction and absence is attenuated by mediating variables such as the absence control policies of the organisation.

This study investigated the association between kinship responsibility and absence. Although increasing kinship responsibility was found to be positively related to increasing number of absence spells in the previous year for female nurses (Fig. 5), no association was found for the male nurses (Fig. 4). This supports suggestions by Miller and Norton (1986), Burton (1992) and Steers and Rhodes (1978) that absence amongst female nurses is influenced by their relationship in caring for their family. The present study, however, does not support Lee and Ericksen's (1990) suggestion that kinship responsibility is the most important external variable influencing absence; the weak relationship found in the present study between kinship responsibility and absence suggests that although kinship responsibility exerts some influence on absence other factors may be more important.

Absence was significantly and negatively correlated to intent to stay for female but not male nurses (Figs 4 and 5). Once more, the association found was weak, suggesting that other factors may be more important. The results for the female registered nurses, however, support Wise's (1993) suggestion that absence, like intent to leave, is associated with turnover. The reason for the lack of a relationship for the male nurses may be the difference in tenure of the male compared to the female registered nurses; Ferris and Rowland (1987) report that low tenure employees who are absent more frequently are less inclined to leave, but that high tenure employees who were frequently absent were more inclined to leave.

Overall, the variants on the original model, illustrated in Figs 3, 4 and 5, show that different variables are associated with different measures of absence and this confirms the different meanings of absence. Absence frequency in the previous year, found to be significantly related to kinship responsibility, for example, is considered to be a measure of "avoidable" absence, i.e. absence not due to sickness (Farrell and Stamm, 1988: Hackett and Guion, 1985). Similarly, job satisfaction was found to be significantly related to the frequency of one-day absence (Fig. 5), threeday absence (Fig. 4) and short-term absence (Fig. 3). Intent to stay was found however to be significantly and negatively correlated to the duration of absence in the previous year, considered to be a measure of unavoidable absence, i.e. absence not due to sickness
(Figs 3 and 5). These results are surprising as one might expect that kinship responsibility would be related to a measure of unavoidable absence, whilst intent to stay would be related to a measure of avoidable absence. The results could be due to problems with reliability of these measures. But it could be that working in the government hospital does allow employees who intend to stay to keep job security even if they take avoidable absence.

In summary, this study provides support for Blegen and Mueller's (1987) and Cavanagh and Coffin's (1992) suggestions that it is erroneous to include male and female nurses in a total sample, although the number of male nurses may be too small to analyse separately. Male and female nurses may differ in what they view as important to encourage them to remain in their job, and in their satisfaction with different job facets.

\section{Conclusion}

A correlational design was used in this study because the variables included in the model are difficult, if not impossible, to manipulate and control. A prospective design would have had the advantage of shedding light on causal relationships between variables but was not possible due to time limitations. Data on job satisfaction, intent to stay and other variables were collected cross-sectionally whilst absence data was collected retrospectively. Studying absence retrospectively results in further problems in determining causation but was preferable, Clark (1975) reports that measuring absence prospectively results in a decrease in absence as staff knew their records were being reviewed (Hawthorn effect). The direction of the relationships illustrated in Figs 3, 4 and 5, therefore, are those inferred by the theoretical framework and cannot be deduced from the results of the present study.

In conclusion, the present study, which is one of relatively few to compare male and female registered nurses, identified important differences between male and female nurses for the relationships between the variables investigated. The study demonstrates that whilst job satisfaction is associated with absence, the hospital's policies for absence control (such as certification of all absence, the possibility of a visit at home from the doctor) were a possible intervening variable attenuating the relationship between these variables.

Most research studies of this kind assume that turnover and absence are always undesirable. These, though, have advantages, both for the organisation and the employee, as turnover allows exit of staff who are not efficient and the entry of innovative ideas, and absence allows employees to maintain physical and mental health (Price and Mueller, 1986; Price and Mueller, 1981; Redfern, 1978; Steers and Rhodes, 1978). However at times of acute staff shortage such as that facing this particular hospital in Malta, turn- 
over and absence must be viewed as undesirable and efforts should be made to limit them.

The implication of this study for future research on job satisfaction, intent to stay and absence, is that data for male and female nurses be analysed separately. The differences between these groups identified in the present study suggest that conclusions may be erroneous if data from both groups are aggregated. Further, to avoid difficulties in inference of causality between variables, prospective designs should be used in studies seeking to establish the relationship between the variables. These studies should include repeated measures of job satisfaction because, as with other attitudinal variables, this does not remain constant.

Further studies are needed to assess the relationship between the variables identified as having a possible influence on intent to stay, that is, expected pay, support with kinship responsibility, fear of change and perceived job security. This would contribute to the development of a causal model of job satisfaction, intent to stay and absence for Maltese nurses.

\section{References}

Blegen, M. A. and Mueller, C. W. (1987) Nurses' job satisfaction: a longitudinal analysis. Research in Nursing and Health 10(4), 227-237.

Brink, P. J. and Wood, M. J. (1989) Advanced Design in Nursing Research. Sage, London.

Brooke, P. P. (1986) Beyond the Steers and Rhodes model of employee attendance. Academv of Management Review 11(2), 345-361.

Buchan, J. (1994) Nursing shortages and human resource planning. International Journal of Nursing Studies 31(5), 460-470.

Burton, R. (1992) Tackling staff absenteeism. Nursing Standard 7(3), 37-40.

Cavanagh, S. J. (1989) Nursing turnover: literature review and methodological critique. Journal of Advanced Nursing 14, 587-596.

Cavanagh. S. J. and Coffin, D. A. (1992) Staff turnover among hospital nurses. Journal of Advanced Nursing 17, 1369-1376.

Chadwick-Jones, J. K., Brown, C. A., Nicholson, N. and Sheppard, C. (1971) Absence measures: their reliability and stability in an industrial setting. Personnel Psychology 24, 463-470.

Clark, J. (1975) Time Out? A Study of Absenteeism Among Nurses. Royal College of Nurses Series, DHSS London.

Farrell, D. and Stamm, C. L. (1988) Meta-analysis of the correlates of employee absence. Human Relations 41(2), 211-227.

Ferris, G. R. and Rowland, K. M. (1987) Tenure as a moderator of the absence-intent to leave relationship. Human Relations 40, 255-265.

Gauci Borda, R. and Norman, I. J. (1997) Factors influencing turnover and absence of nurses: a research review. International Journal of Nursing Studies.

Hackett, R. D. and Guion, R. M. (1985) A re-evalu- ation of the absenteeism-job satisfaction relationship. Organisational Behaviour and Human Decision Making Process 35, 340-381.

Hammer, T. H. and Landau, J. (1981) Methodological issues in the use of absence data. Journal of Applied Psychology 66, 574-580.

Haughey, B. P. (1994) Research: evaluating quantitative research designs part I. Critical Care Nurse October, pp. 100-102.

Landstrom, G. L., Biordi, D. L. and Gilles, D. E. (1989) The emotional and bchavioural process of staff nurse turnover. Journal of Nursing Administration 19(9), 23-28.

Lee, J. B. and Eriksen, L. R. (1990) The effects of a policy change on three types of absence. Journal of Nursing Administration 20(7/8), 37-40.

Locke, E. A. (1969) What is job satisfaction? Organizational Behaviour and Human Performance 4, 309336.

Locke, E. A. (1976) The nature and causes of job satisfaction. In: M. D. Dunnette (ed). Handbook of Industrial and Organisutional Psychology. Rand McNally, U.S.A.

Lyons, T. M. (1971) Role clarity, need for clarity, satisfaction, tension and withdrawal. Organizational Behaviour and Human Performance 6, 99110.

Matrunola, P. (1996) Is there a relationship between job satisfaction and absenteeism. Journal of Advanced Nursing 23, 827-834.

Metcalf, C. A. (1986) Job satisfaction and organizational change in a maternity hospital. International Journal of Nursing Studies 23(4), 285-298.

Michaels, C. E. and Spector P. E. (1982) Causes of employee turnover: A test of the Mobley, Griffeth and Meglino model. Journal of Applied Psychology 67(1), 53-59.

Miller, D. S. and Norton, V. M. (1986) Absenteeism: nursings services' albatross. Journal of Nursing Administration 16(3), 38-42.

Mobley, W. H. (1977) Intermediate linkages in the relationship between job satisfaction and employee turnover. Journal of Applied Psychology 62(2), 237240.

Mueller, C. W. and McCloskey, J. C. (1990) Nurses' job satisfaction: a proposed measure. Nursing Research 39(2), 113-117.

Newman, J. E. (1974) Predicting absenteeism and turnover: a field comparison of Fishbein's model and traditional job attitude measures. Journal of Applied Psychology 59(5), 610-615.

$\mathrm{Ng}$, C. (1991) Work attendance study. Senior Nurse 11(4), 12-16.

Nichols, G. A. (1971) Job satisfaction and nurses' intentions to remain with or to leave an organization. Nursing Research 20(3), 218-228.

Nicholson, N., Brown, C. A. and Chadwick-Jones, J. K. (1976) Absence from work and job satisfaction. Journal of Applied Psychology 61(6), 728-737.

Nicholson, N. (1977) Absence behaviour and attendance motivation : a conceptual synthesis. Journal of Management Studies 41, 231-252.

Parasuranmam, S. (1989) Nursing turnover: an integrated model. Research in Nursing and Health 12, 267-277.

Polit, D. F. and Hungler, B. P. (1991) Nursing 
Research: Principles and Methods, 4th edn. J. B. Scott, K. D. and Taylor, G. S. (1985) An examination Lipincott, U.S.A.

Porter, L. W. and Steers, R. M. (1973) Organizational, work and personal factors in employee turnover and absenteeism. Psychological Bulletin 80(2), 151176.

Price, J. L. and Mueller, C. W. (1981) Professional Turnover: The Case for Nurses. S.P. Medical and Scientific Books, New York.

Price, J. L. and Mueller, C. W. (1986) Absenteeism and Turnover of Hospital Employees. JAI Press, Greenwich, CT.

Redfern, S. J. (1978) Absence and wastage in trained nurses: a selective review of the literature. Journal of Advanced Nursing 3, 231-249.

Redfern. S. J. (1981) Hospital Sisters: Their Job Attitudes and Occupational Stability. Royal College of Nursing, London. of conflicting findings on the relationship between job satisfaction and absenteeism: A meta-analysis. Academy of Management Journal 28(3), 599-612.

Seybolt, S. W. (1986) Dealing with premature employee turnover. Journal of Nursing Administration 16(2), 26-32.

Steers, R. M. and Rhodes, S. R. (1978) Major influences on employee attendance: a process model. Journal of Applied Psychology 63(4), 391-407.

Taylor, J. C. (1977) Job salisfaction and quality of working life: a reassessment. Journal of OCCupational Psychology 50, 243-252.

Wise, L. C. (1993) The erosion of nursing resources: employee withdrawal behaviours. Research in Nursing and Health 16, 67-75. 